\title{
Android based Traffic Rules Violation Detection System "Vehitrack"
}

\author{
D. R. Agrawal \\ Assistant Professor \\ Department of Computer \\ Science and Engineering \\ SNJB's Kantabai Bhavarlalji \\ Jain College Of Engineering, \\ Chandwad
}

\author{
Kasliwal Komal S. Gandhi Labhesh R. Deore Punam D. Saitwal Pooja D
}

\begin{abstract}
The main objective of the project is to detect the traffic rule violator on road by means of sensor, RFID reader and RFID tag technology and capture image by means of camera. The system will control the traffic density of the specific location. The project will also focus on mobile application which will help to know information about the vehicle tracked by sensor on road. This mobile app will maintain the database related to image as proof and RFID Tag number such as name, address, license number, photo, mobile number, their bank account number and also the list of previous rules broken with image as proof, date and time and fine paid by vehicle owner. This all data about the vehicle will display on smart phone of traffic police. This application will automatically receive the fine from the owner bank account and send the message to their mobile application or number about the rules and their fine. If same vehicle found to be encountered again and again then a specific action could be done.
\end{abstract}

\section{Keywords}

RFID Tag, RFID Reader, IR Sensor, Camera and Android Application

\section{INTRODUCTION}

According to the increasing population of peoples and vehicles on the road used by those peoples, there are many issues created like traffic violation, security of peoples, increasing accidents on road side and also increasing the workload of traffic police and government too. This project will reduce all these issues occurred in throughout the world. In this project there is automatic traffic rules violation detection system, message sending, receiving and automatic fine receiving from user's bank account.[1]

In this project, sensor will sense the RFID tag number which is given to the individual vehicle while purchasing or passing the vehicle for the number plate received by RTO. The camera will also be there for capturing the image of vehicle who have broken the rule. RFID reader will read the RFID tag number, latest image capture by camera and send this information to the server database. Server Database will send the Information related to RFID tag number and image on traffic police android application 'Vehitrack' after the rule broke by vehicle owner. This 'Vehitrack' application will received the RFID tag number and related image from server and related details about that particular vehicle such as name of owner, address of owner, license number, plate number, photo of vehicle user, mobile number, their bank account number and also the list of previous rules broke by that vehicle owner or driver with the date, time, fine and the type of rule. This application will received the fine automatically from the owner's bank account according to the rule broken by vehicle driver and its actual fine decided by government.

This application will also send the message to vehicle owner about the type of rule broken by vehicle user, fine according to that rule, proof of breaking the rule in the form of image taken by camera, date and time of breaking the rule and accurate amount receiving by their bank account as fine paid for breaking the rule.[4]

Due to this whole process there will be reduction in the workload of traffic police and government and also reduction in accidents and corruption too.

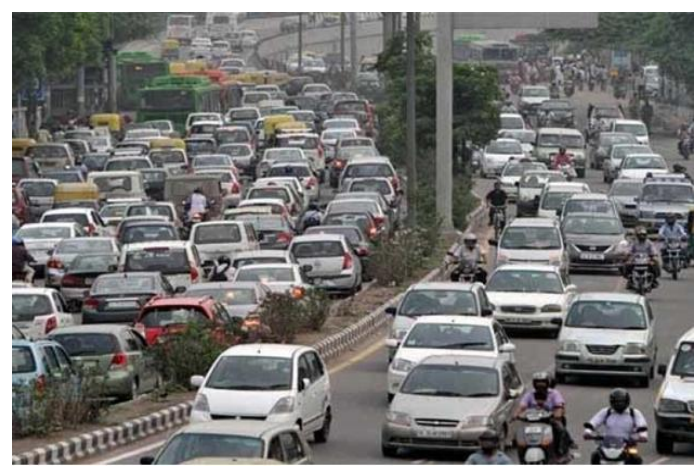

Figure 1:Traffic of India

\subsection{Need}

- As increasing traffic violation, rules violation due to traffic and corruption problem and many other issues are created. On the basis of literature survey of all existing system, all system works 
manually and does not receive the fine automatically due to this corruption increases.

- This project will reduce the traffic problems; minimize the traffic rules violation on road.

- It make fine collection easy due to automatic fine reductionfrom owners bank account according to rule broke by vehicle user or owner and the actual fine.

- It maintains the transparency between peoples and government authority due to which there is reduction in corruption in the world.

\subsection{Working}

The project will reduce all the issues related to traffic rule violation on road. In this system there are automatic traffic rules violation detection devices, message sending and automatic fine receiving from owner's bank account. In this system, RFID reader will read the RFID tag number which is given to the individual vehicle while purchasing or passing the vehicle for the number plate received by RTO which will be mandatory. The camera will also be there for capturing the image of vehicle that has broken the rule. RFID reader will read the RFID tag number, latest image capture by digital camera and send this information to the server database. Server Database will send the Information from its stored database related to RFID tag number and image on traffic police android application 'Vehitrack' after the rule broken by vehicle user or owner. This 'Vehitrack' application will received the RFID tag number and related image from server and related details about that particular vehicle such as name of owner, address, license number, passing number, photo, mobile number, their bank account number and also the list of previous rules broke by that vehicle owner or driver with the date, time, fine and the type of rule.

This application will received the fine automatically from the owner's bank account according to the rule broken by vehicle driver and its actual fine decided by government. This application will also send the message to vehicle owner about the type of rule broken by them, fine according to that rule, proof of breaking the rule in the form of image capture by digital camera, date and time of breaking the rule and accurate amount receiving by their bank account as fine paid for breaking the rule. According to this whole process done, there will be reduction in the workload of traffic police and government and also reduction in accidents and corruption too in world.

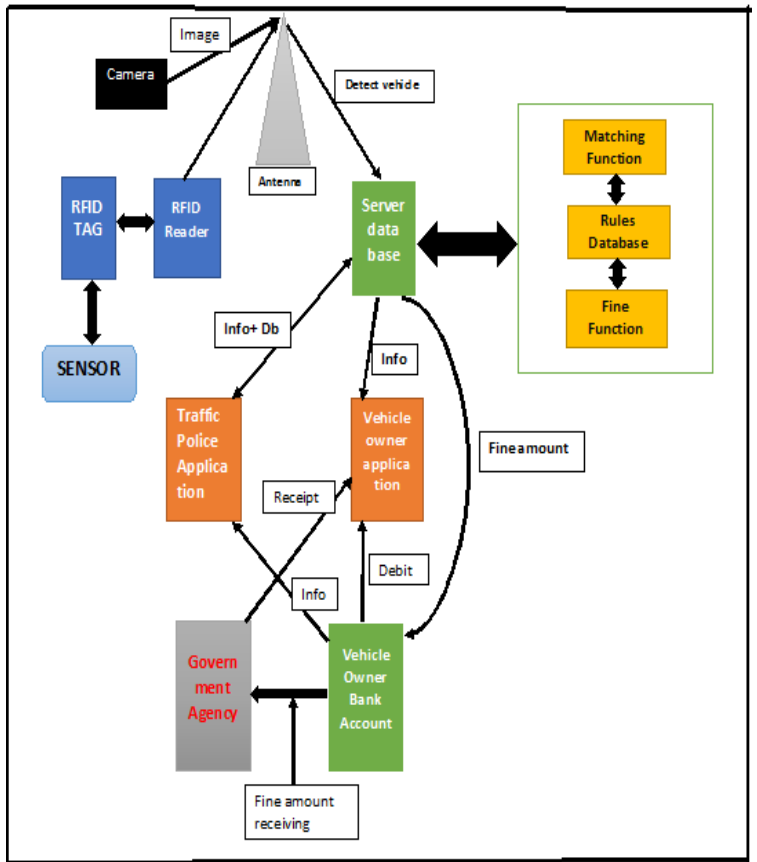

\section{LITERATURE SURVEY}

According to the increasing population of peoples and vehicles on the road used by those peoples, there are many issues created like traffic violation on road, security of peoples from accidents, increasing accidents on road side and also increasing the workload of traffic police and government too. In this survey we have mentioned different Traffic rule Violation detection Devices. [5]

\subsection{Existing System}

Different Traffic Rule Violation Detection Devices are

Available in Market. They are as follows:

1) Embedded System [6]

2) Traffic detection system using Android [2]

3) RFID Technology for smart Vehicle control using Traffic signal speed limit tag communication [3]

4) Violation Detection at Traffic Signals using RFID System [1]

\subsection{Proposed System (Vehitrack)}

Our current application is to detect the traffic rule violator on road by means of sensor, RFID reader and RFID tag technology and capture image by means of camera. The system will control the traffic density of the specified location. The project will also focus on mobile application which will help to know information about the vehicle tracked by sensor and camera on road.

This mobile application will maintain the database related to capture image through camera as proof and RFID Tag number such as name of owner, address of owner, license number, photo of vehicle user, mobile number, their bank account number and also the list of previous rules broken with image as proof, date and time and fine paid by vehicle owner. This all data about the vehicle will display on smart phone of traffic police. 
This application will automatically receive the fine from the owner bank account and send the message to the user mobile application or about the number the rules and their fine. If same vehicle found to be encountered again and again then a specific action could be done.

- First module:Detect the vehicle at signal for breaking rules using sensor, RFID Reader and Tag and capture the image by using camera.

- Second module:Camera capture the image of vehicle, sensor sense the vehicle RFID tag no, RFID reader reads it and send that information to the server database.

- Third module:Implementation of Android application for both vehicle user and traffic police by doing the connectivity between the RFID readers, Server Android application.

- $\quad$ Fourth module:The fine of breaking rule will be received automatically by the owner bank account and also message will be send to vehicle owner and traffic police mobile application.

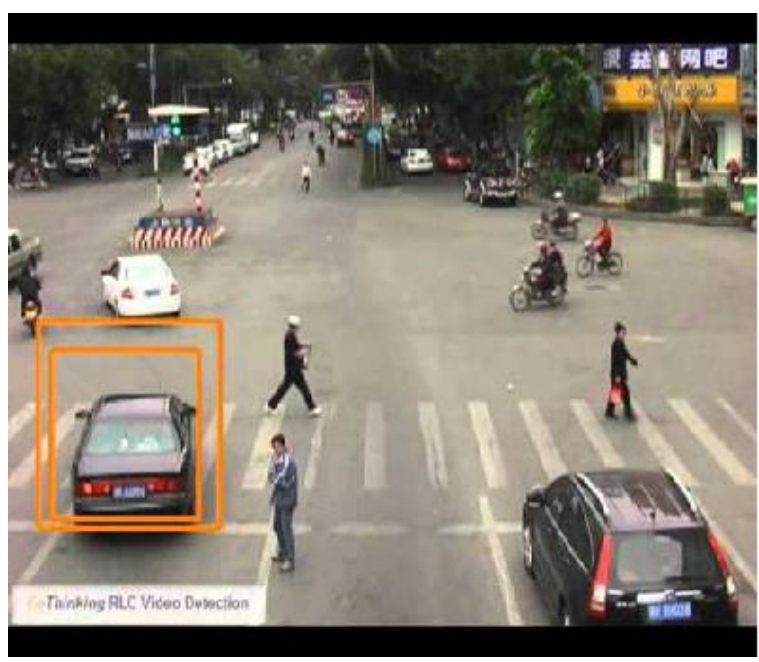

Figure-: Rule broken by Car

\subsection{Features of proposed system}

The different features in this proposed system are:-

1) Application Interface

2) Corruption Avoidance

3) Automatic fine collector

4) Reduce workload of Traffic Police

\subsection{Difference between Existing system and Proposed system \\ Table-: Literature Survey}

\begin{tabular}{|c|c|c|c|c|c|}
\hline Parameter & $\begin{array}{l}\text { Embedded } \\
\text { System }\end{array}$ & $\begin{array}{l}\text { Traffic detection } \\
\text { system using Android }\end{array}$ & $\begin{array}{l}\text { RFID Technology for } \\
\text { smart Vehicle } \\
\text { control using Traffic } \\
\text { signal \& speed limit } \\
\text { tag communication }\end{array}$ & \begin{tabular}{|l|} 
Violation \\
Detection at \\
Traffic Signals \\
using RFID System
\end{tabular} & \begin{tabular}{|l} 
Proposed System \\
\end{tabular} \\
\hline Definition & $\begin{array}{l}\text { IR Sensors are } \\
\text { used to measure } \\
\text { density of the } \\
\text { vehicles which } \\
\text { are fixed with in } \\
\text { fixed distance }\end{array}$ & $\begin{array}{l}\text { It Determined } \\
\text { behaviour of traffic } \\
\text { in a particular } \\
\text { location. It calculates } \\
\text { the speed of vehicles } \\
\text { on the basis of } \\
\text { sensors. If any such } \\
\text { obstruct found, then } \\
\text { driver provided an } \\
\text { option to send } \\
\text { message regarding } \\
\text { high traffic his friends. }\end{array}$ & $\begin{array}{l}\text { Is used to reduce } \\
\text { these reckless } \\
\text { accidents for which } \\
\text { we propose a } \\
\text { system that governs } \\
\text { and controls the } \\
\text { speed of the vehicle } \\
\text { without any direct } \\
\text { inconvenience to } \\
\text { the driver. }\end{array}$ & $\begin{array}{l}\text { We can integrate } \\
\text { RFID tag on very } \\
\text { vehicle which can } \\
\text { be read by RFID } \\
\text { Reader, if any } \\
\text { violate the rule of } \\
\text { traffic signal then } \\
\text { it read RFID tag } \\
\text { number of that } \\
\text { vehicle send the } \\
\text { info to computer } \\
\text { office. }\end{array}$ & $\begin{array}{l}\text { RFID tag on very } \\
\text { vehicle which can be } \\
\text { read by RFID Reader, } \\
\text { if any violate the rule } \\
\text { of traffic signal then } \\
\text { it read RFID tag } \\
\text { number of that } \\
\text { vehicle send the info } \\
\text { to smart phone and } \\
\text { automatically fine is } \\
\text { received by vehicles } \\
\text { owner Bank account. }\end{array}$ \\
\hline \begin{tabular}{l|} 
Device \\
Dependency
\end{tabular} & Microcontroller & GPS & \begin{tabular}{|l|} 
RFID System \\
\end{tabular} & $\begin{array}{l}\text { RFID Tag \& RFID } \\
\text { Reader PC. }\end{array}$ & \begin{tabular}{|l|} 
RFID Tag \& RFID \\
Reader, camera as \\
well as Android \\
\end{tabular} \\
\hline $\begin{array}{l}\text { Way of } \\
\text { Detection }\end{array}$ & $\begin{array}{l}\text { Measure Density } \\
\text { of Vehicles }\end{array}$ & $\begin{array}{l}\text { Calculates speed of } \\
\text { Vehicles }\end{array}$ & $\begin{array}{l}\text { Control the speed of } \\
\text { Vehicle without any } \\
\text { direct } \\
\text { inconvenience to } \\
\text { the driver }\end{array}$ & RFID System & $\begin{array}{l}\text { RFID System \& } \\
\text { Android phone }\end{array}$ \\
\hline $\begin{array}{l}\text { Automatic } \\
\text { fine reduced }\end{array}$ & NO & NO & NO & NO & YES \\
\hline $\begin{array}{l}\text { Maintain } \\
\text { Database }\end{array}$ & NO & NO & NO & YES & YES \\
\hline Useful & NO & NO & NO & NO & YES \\
\hline $\begin{array}{l}\text { Extra } \\
\text { Feature }\end{array}$ & NO & NO & NO & NO & YES \\
\hline
\end{tabular}

\section{USER INTERFACES}

User interface is a key part of any system. As we know,there are different types of user interface like commandline UI, Graphical User Interface (GUI) etc. GUI is more understandable than other UI. User interface of Vehitrack will be interactive and GUI base. User can easily use application.

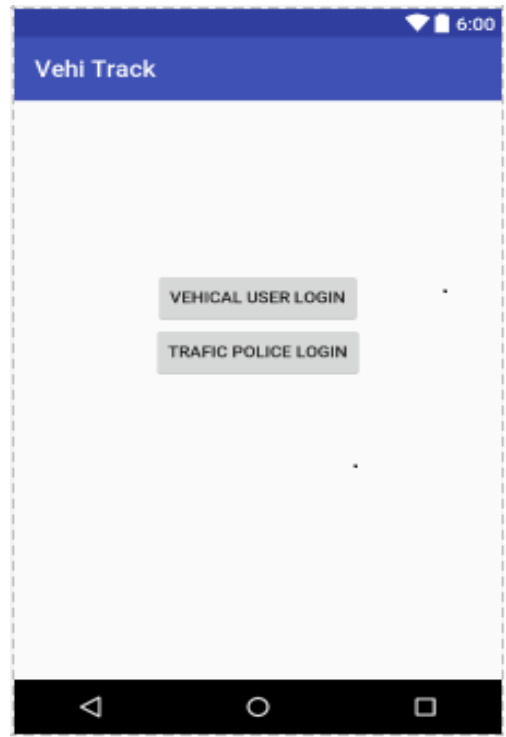

Figure-: Main Page of Android Application 


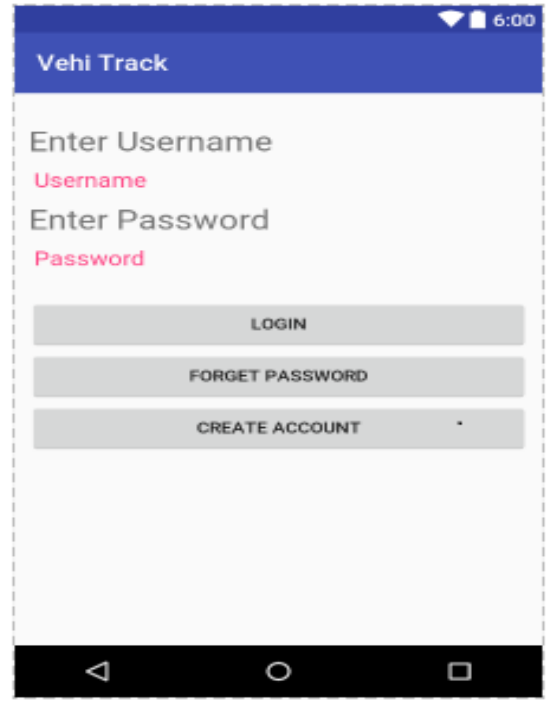

Figure-: Login Page

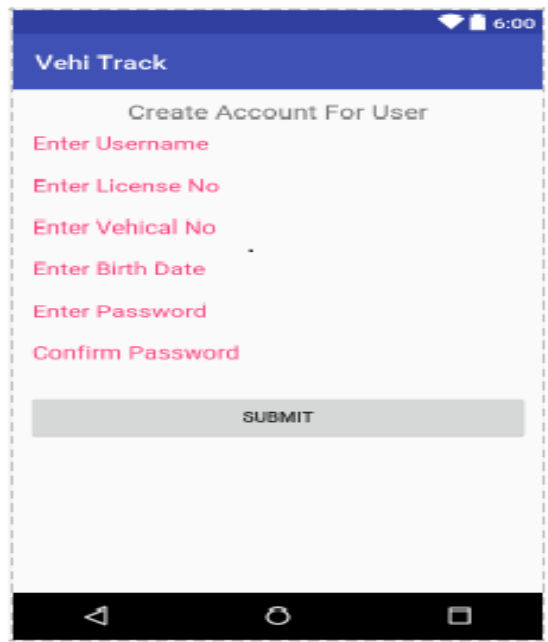

Figure-: Create Account for Vehicle User

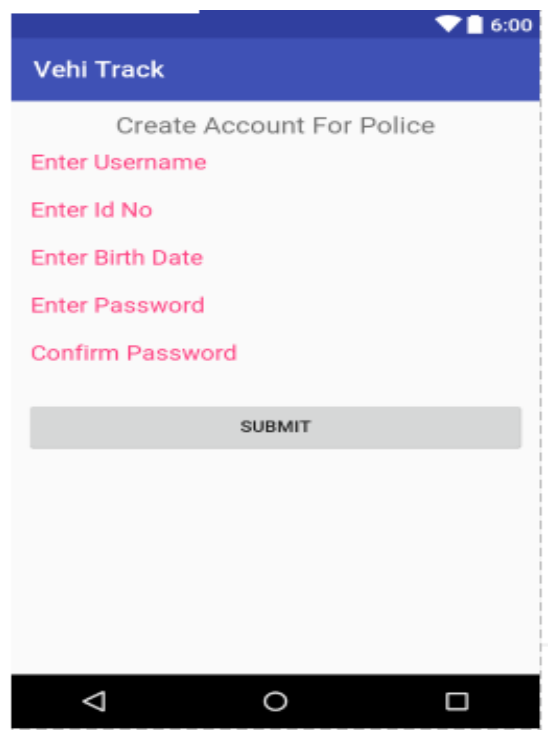

Figure-: Create Account for Traffic Police

\section{CONCLUSION}

Chapter 1: Introduction This chapter contains the overall description of the project. The terms included in this chapter are elaborated in the further chapter of conclusion.

Chapter 2: Literature Survey This chapter consists of

the disadvantages of already existing systems with a table to distinguish among all the available applications. It also consists of the advantages and features to be added in current system.

Chapter 3: User Interface This chapter consist of GUI

designs of android application for vehicle user and traffic police also.

Traffic Management System is a complex task. Traffic

Management System will help us to reduce the headache of Traffic Policeman. We have seen all existing systems with their characteristics in preliminary survey.This project will greatly reduce the drawbacks of existing system. It provides the necessary security and protection.

\section{REFERENCES}

[1] Imperial Journal of Interdisciplinary Research (IJIR) Vol-2, Issue-5, 2016 ISSN: 2454-1362, http://www.onlinejournal.in Violation Detection at Traffic Signals Using RFID System.

[2] Journal of Advanced Computing and Communication Technologies (ISSN: 2347 - 2804) Volume No. 3 Issue No. 3, June 201556 Traffic Detection System Using Android.

[3] International Journal of Computer Applications (0975 - 8887) Volume 43- No.14, April 201238 RFID Technology for Smart Vehicle Control using Traffic Signal Speed Limit Tag Communication.

[4] http://www.slideshare.net/editorijritcc1/ automaticvehicle-accident detection- and-Traffic-controlsystem

[5] http://www.slideshare.net/IISTech2015/implementing -intelligent-trafficcontrol- System-for- congestioncontrol-ambulance-clearance-and-stolenvehicledetection

[6] http://www.slideshare.net/louiseantonio58/imageprocessing-basedintelligent- traffic-Control-system matlab-gui 